\title{
A Case of Thyroarytenoid Myoneurectomy Using LASER and Monopolar Electrical Device in Spasmodic Dysphonia
}

\author{
So Jeong Lee (D), Soo Yeon Jung (D), Sung Min Chung (D), and Han Su Kim (D) \\ Department of Otorhinolaryngology-Head and Neck Surgery, Ewha Womans University School of Medicine, Seoul, Korea
}

\author{
연축성 발성장애 환자에서 레이저와 단극성 전기소작기를 이용한 갑상피열근신경 절제술 1 예 \\ 이소정, 정수연, 정성민, 김한수 \\ 이화여자대학교 의과대학 이비인후과학교실
}

Spasmodic dysphonia is a focal laryngeal dystonia that results in involuntary spasms during speech. The etiology of spasmodic dysphonia is not yet defined, but it is presumed to be a neurological abnormality of central nervous system motor function. The treatment of choice for spasmodic dysphonia is botulinum toxin injection directly at the laryngeal muscles. However botulinum toxin injection requires repeated procedures. Many different kinds of surgical treatments have been introduced but the recurrence rate is still high. So we performed myomectomy with LASER and neurectomy with specially designed electrical surgical knife which can cut recurrent laryngeal nerve branch selectively with its noble curved section. We report a case of a 43-year-old male patient with spasmodic dysphonia treated by thyroarytenoid myoneurectomy.

Keywords Spastic dysphonia; Thyroarytenoid muscle; Myectomy; Denervation.

\section{서 론}

연축성 발성장애는 후두에 국한된 근긴장 이상(dystonia)으로 후두근의 불수의적인 연축에 의해 비자발적으로 나타나는 신경성 발성장애이다. 후두 운동에 관여하는 중추 신경계의 이상 또는 기저핵의 운동 조절 부위의 이상으로 발생하는 것으로 추정되나 대 부분 명확한 원인을 찾기 어렵다.) 발성 시 작업특이적이며(task-specificity), 비자발적인 음성의 떨림이 나타나며 발성 노력으로 성대가 쉽게 피로해지고 간헐적 음성 멈춤 증상 도 있다.

후두 근육 내 보툴리눔 독소 주입술은 가장 널리 사용되고 있는 치료 방법이나 주입 직후 수 일간 쉰 목소리가 발생하며 치료 효과의 지속 시간이 짧아 반복적인 주입이 필 요하고 보툴리눔 독소에 대한 내성이 발생하면 주입 용량을 늘려야 하는 제한점이 있 다. 그동안 이러한 단점을 극복하려는 다양한 수술적 치료 방법들이 시도되어 왔다.2) 이
Received July 15, 2019

Revised August 26, 2019

Accepted September 26, 2019

\section{Corresponding Author}

Han Su Kim, MD, PhD

Department of Otolaryngology-Head and Neck Surgery, Ewha Womans University School of Medicine, Mokdong Hospital, 1071 Anyangcheon-ro, Yangcheon-gu, Seoul 07985, Korea

Tel +82-2-2650-2686

Fax+82-2-2648-5604

E-mail sevent@ewha.ac.kr

\section{ORCID iDs}

So Jeong Lee (iD)

https://orcid.org/0000-0001-9055-635X

Soo Yeon Jung (iD)

https://orcid.org/0000-0001-7497-3057

Sung Min Chung (D)

https://orcid.org/0000-0002-7808-4094 Han Su Kim (iD)

https://orcid.org/0000-0003-2239-0225

This is an Open Access article distributed under the terms of the Creative Commons Attribution Non-Commercial License (https://creativecommons.org/ licenses/by-nc/4.0) which permits unrestricted non-commercial use, distribution, and reproduction in any medium, provided the original work is properly cited. 
론적으로 근긴장 이상이 발생하는 갑상피열근 및 여기에 분 포하는 반회후두신경의 분지를 선택적으로 절제하는 것이 가장 이상적이나 현수후두경 수술 시 제한된 시야 내에서 이 러한 목적을 달성하기가 쉽지 않았다. 본 증례에서는 레이저 를 이용하여 갑상피열근을 일부 절제한 후 반회후두신경의 갑상피열근 분지를 특별히 고안된 전기소작기구를 이용하여 선택적으로 절단하는 수술을 성공적으로 시행하였기에 보고 하는 바이다.

\section{증 례}

43세 남자 환자가 8개월부터 목소리가 쉬고 3개월 전부터 의 발성 시 목소리가 떨리는 증상이 있어 2017년 4월 19일 내 원하였다. 동반 증상으로는 노력성 발성, 음성 피로, 목 이물 감, 헛기침이 있었다. 은행 상담 업무를 하며 음주력은 주 소 주 1 병 정도이고 흡연력은 없었다.

내원 시 시행한 후두 스트로보스코피에서 발성 시 피열연 골의 비특이적인 내전 양상이 보였고 성대의 전후방 수축, 가 성대의 내측 접근이 혼합된 4형 근긴장성 발성장애 소견이 보 였다. 음향학적 검사에서는 jitter $18 \%$, shimmer $24 \%$, noise harmonic ratio(NHR) 0.78 이었으며, voice range profile 검 사에서는 정상 음역대를 보이나 pitch break가 있고 진폭이 감소한 양상을 나타냈다.

연축성 발성장애 및 이에 동반된 보상성 근긴장성 발성장애 로 진단을 하고 3개월 동안 약물 치료(clonazepam, $0.25 \mathrm{mg}$, $\mathrm{tid}$ )와 총 10 회의 음성 치료를 시행하였다. 그러나 증상이 크 게 완화 되지 않아 양측 갑상피열근에 각각 2.5 unit의 보툴리 눔 독소를 주입하였다. 보툴리눔 독소 주입 6개월 뒤 다시 증 상이 악화되여 2개월간 약물치료(clonazepam $0.25 \mathrm{mg}$, bid) 및 리도카인 가글을 시행하였으나 증상의 호전과 악화를 반 복하였다. 이에 보툴리눔 독소의 재주입을 권하였으나 환자가 좀 더 영구적인 치료를 원하여 갑상피열근 절제 및 반회후두 신경의 갑상피열근 분지의 선택적 절단술을 시행하였다.

수술 방법은 다음과 같았다. 전신마취하에 현수후두경으 로 양측 진성대 및 가성대의 일부를 노출시켰다. 이후 $\mathrm{CO}_{2}$ 레 이저(3.5 watt, continuous superpulse mode)로 갑상피열근 의 외측부의 부분 절제술을 시행하였다. 절제 범위의 내측 경 계는 성대 진동면과 후두실(laryngeal ventricle) 이행부에서 $1 \mathrm{~mm}$ 외측 지점이었으며, 가쪽 경계는 갑상연골의 연골막이 노출되는 부분까지로 정하였다. 전방 경계는 갑상연골의 연골 막이 후두실의 첨단과 만나는 부분이고 후방 경계는 후두실 이 끝나는 부분으로 가급적 갑상피열근의 외측 부분이 모두 절제 범위에 포함되도록 하였다(Fig. 1). ${ }^{2}$ 평균적인 근 절제의
깊이는 3 5 mm였으며 측정은 suction을 이용하여 촉진으로 확인하였다.

이후 반회후두신경의 갑상피열근 분지를 Tsuji가 개발한 전 기소작기구를 이용하여 선택적으로 절단하였다.2) 이 기구는 needle 형태의 monopolar 전기소작기로 $8 \mathrm{~mm}$ 길이의 말단 부분이 본체와 30 도 각도로 굽어 있고 그 끝에 $2.5 \mathrm{~mm}$ 길이 의 갈고리 형태로 전기가 통하는 첨단이 있는 형태로서 일반 적으로 사용하는 전기소작기구의 generator[Medtronics, Minneapolis, MN, USA; Valley lab, Force FX(TM), 강도 20] 에 연결하여 사용할 수 있다(Fig. 2).

반회후두신경의 갑상피열분지는 측윤상피열근막, 갑상피 열근막과 갑상연골막의 내측 사이로 주행해서 갑상피열근으 로 분포한다. 레이저를 이용해 갑상피열근 부분 절제술을 시 행한 후 Tsuji의 전기소작기를 갑상피열근 절제술 시행 범위 의 후방 경계, 피열연골의 근육돌기 외측에 뒤쪽으로 굽히며 넣었다. 이후 축을 중심으로 도구를 외측으로 45 90도 정도 바깥으로 돌리면서 기구의 첨단이 갑상연골연골의 내측에 닿 는 느낌을 확인하고 위로 잡아 당기면서 첨단에 갑상피열근 분지가 당겨져 올라오는 것을 확인 후 선택적으로 소작하여 절단했다. 수술은 양측 성대 모두 같은 방법으로 시행했다.

수술 후 1 일째 후두 내시경 검사상 양측 성대 움직임은 정 상이었으며 성대 위축이나 휘어짐 소견이 관찰되지 않았고 환 자의 주관적인 증상과 쥐어짜는 듯한 목소리도 호전되었다 (Fig. 3). 환자는 수술 후 1년 동안 목소리 분절, 재발, 호흡기 능장애, 흡인 등 부작용 없었으며 외래에서 추적 관찰 중이다.
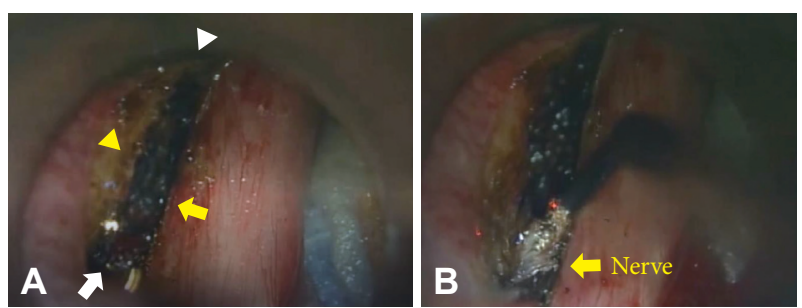

Fig. 1. Intraoperative view of vocal folds. $\mathrm{CO}_{2}$ laser resection of left thyroarytenoid muscle. Resection was done medially to the $1 \mathrm{~mm}$ lateral to the border between the floor of the ventricle and the vocal fold (yellow arrow), laterally as possible as laser beam can reach (yellow arrowhead), posteriorly till the posterior apex of the ventricle(white arrow) and anteriorly to the anterior apex of the ventricle (white arrowhead) (A). Coagulation of thyroarytenoid branch of recurrent laryngeal nerve using specialized surgical knife (B).

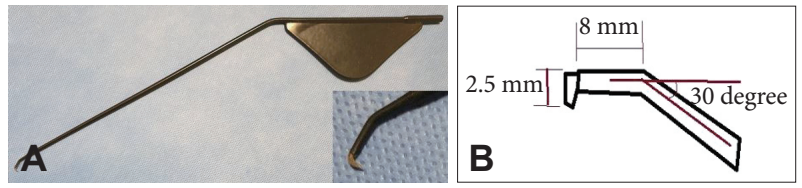

Fig. 2. Electrical surgical knife invented by Tsuji. Photo of electrical surgical knife (A). Details of instrument $(B)$. 


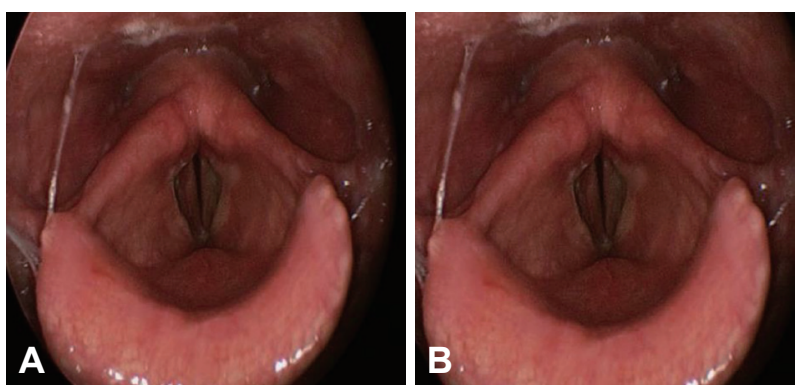

Fig. 3. Post-operative laryngoscopic finding. The mobility of vocal folds was intact. The atrophy or bowing of both vocal folds were not noted. Adduction (A). Abduction (B).

\section{고 찰}

연축성 발성장애의 원인은 중추신경계 운동 조절 문제로 생각하고 있으나 아직 명확히 밝혀지지 않은 상태이다. 근본 적 치료가 어려워 약물 치료, 후두근 내 보툴리눔 독소 주입 술, 수술적 치료 등 다양한 치료가 시도되고 있다. 확립된 치 료법은 없으나 현재 통용된 치료는 후두 근 내 보툴리눔 독소 주입술이다. 하지만 병인에 근거한 근본적인 치료 방법이 아 니라 증상 완화만을 목적으로 하고, 보툴리눔 독소의 약효가 지속적이지 못하므로 반복적인 주입이 필요하여 번거로울 뿐 만 아니라 치료 비용이 많이 든다. 경우에 따라 전신적인 근 쇠약감이 있을 수 있고 독소에 내성이 생겨 점차 주입량을 늘 려야 하는 단점이 있다. 용량-반응 곡선이 개인마다 다르므 로 용량 결정이 어렵고 주입 후 초반에 음성이 불안정하기도 하고 기도 흡인이 있을 수 있다. 또한 임산부에 대한 안정성이 확보되지 않은 제한점도 있다. ${ }^{3}$

연축성 발성장애의 수술적 치료로는 1976년 Dedo가 시도 한 일측성 반회후두신경 절단술(recurrent laryngeal nerve section)이 처음이다. 이는 치료 효과가 오래 지속되는 장점이 있으나 일부 환자에서 성대마비로 인한 호흡 이상이 보고되 었고 반회후두신경의 분지가 재분배되면서 몇 년 지나지 않 아 증상이 재발하는 문제점이 보고되었다.4) 1975 1982년까지 일측성 반회후두신경 절단술을 받은 환자 243명을 대상으로 시행한 설문지와 음성 녹음, 음향 분석(acoustic analysis), 인 지 음성 평가(perceptual voice evaluation)를 바탕으로 도출 된 논문에서 $15 \%$ 에서 6 24개월 내에 중등도 이상의 경련성 음성이 보였다.5) 술 후 확실하게 증상이 호전됨에도 불구하고 반회후두신경 절단술은 인위적으로 일측성 성대마비를 유발 하는 침습적인 시술로 장기적으로 재발률이 증가하는 경향이 있어 널리 사용되지 못했다.)

반회후두신경 분쇄술(avulsion)은 절단술의 변형으로 신경 의 재생을 막아 질병의 재발을 확실하게 예방하고 해당 후두 근의 반마비를 유도하는 방법이다. 수술 후 3 7년 동안 18명
의 환자를 관찰한 연구에서 2 명은 신경 재생으로 증상이 재 발했고 6명은 호흡장애로 내전형갑상성형술을 받았다. ${ }^{7}$

성대를 내전시키는 반회후두신경의 3가지 분지(갑상피열, 측윤상피열, 피열) 중 갑상피열분지만을 선택적으로 자르는 선택적 갑상피열분지 절단술(selective thyroarytenoid nerve section)은 성대 내전 운동에 영향은 없으면서 연축을 조절할 수 있는 장점이 있으나 분지의 특성상 절단 후 신경재분배 $\left(\mathrm{re}^{-}\right.$ innervation) 발생이 많아 재발이 심심치 않게 보고되었다.6,8)

선택적 갑상피열분지의 절단과 경신경고리신경 재지배술 (selective thyroarytenoid nerve section and ansa cervicalis reinnervation)은 갑상피열근에 분지하는 반회후두신경의 근위부를 절단하고 원위부를 경신경고리(ansa cervicalis)와 문합하여 양측 갑상피열근을 영구적으로 탈분극시키고 흥골 설골근으로 신경재분배를 시키는 방법이다. 갑상피열분지만 선택적으로 절단하므로 성대 내전 기능에 적은 영향을 미치

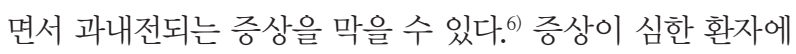
서는 재발을 막고 효과를 높이기 위해 외측윤상피열근 절제 술(lateral cricoarytenoid section)도 함께한다. 이 수술 방법 은 진전(tremor)이 없는 내전형 연축성 발성장애 환자에게만 효과가 있고 외전형 연축성 발성장애나 본태성 음성 진전이 있는 환자에겐 효과가 없으며 경부 접근법으로 현수후두경하 수술에 비해 침습적인 제한점이 있다.6.9)

2000년 Issiki 등이 발표한 제2형 갑상성형술(type II thyroplasty, midline lateralization of thyroplasty)은 치료 1년 뒤 $66.7 \%$ 환자만이 증세가 호전된 채로 유지되었으나 이 중 중등도 이상의 호전을 경험한 환자는 오직 $22.2 \%$ 뿐으로 증 상 호전이 지속적으로 유지되지 않는 제한점이 보고되었다. ${ }^{10)}$

20명의 환자에서 양측 갑상피열 근절제술(thyroarytenoid myectomy)을 시행한 연구에서는 수술 직후 효과는 좋았으 나 6개월이 지나면서 효과가 감소했고 12 개월 뒤에는 절반 정 도의 환자가 다시 보툴리눔 독소 주입술이 필요했다.,111) 7명 의 환자에서 미세후두현미경을 이용해 전교련부터 성대돌기 까지 갑상피열근절제술을 시행한 연구에서는 수술 직후 기식 성음성(breathiness)이 3 6개월 정도 지속되는 합병증을 보 고하였다. ${ }^{12)}$

이처럼 다양한 외과적 수술법들이 시행되었지만 수술의 침 습성 및 난이도, 합병증, 부작용, 그리고 성공률을 고려하였 을 때 성대 내 보톡스 주입술에 비해 월등한 효과를 보이는 수술법은 없는 상황이다. 본 저자들이 시행한 미세후두현미 경 하 근절제술 및 선택적 신경절제술은 여러 외과적 수술법 의 단점을 보완하면서 치료 효과를 극대화하고자 하는 노력 의 일과이다. 미세후두현미경을 이용한 경구 강접근은 경부 접근에 비해 수술 흥터가 없고 비침습적이다. 또한 현미경으 
로 확대된 시야를 확보하여 진성대 점막에 손상을 주지 않고 $\mathrm{CO}_{2}$ 레이저를 이용해 갑상피열근의 외측을 선택적으로 제거 할 수 있다. 신경절제술 후 발생하는 신경재분배는 갑상피열 근에 분포하는 여러 개의 분지를 완벽히 제거하지 못하기 때 문에 발생하는 합병증이다. 기존 술식은 신경이 진입하는 부 분으로 예상되는 부분을 레이저 또는 전기소작기로 태우는 방식으로 과도할 경우 주변 정상 점막 및 갑상피열관절에 손 상을 유발할 수 있기 때문에 이를 예방하기 위해 충분하게 신 경분지를 파쇄하지 못하여 남은 신경분지에서 재분배가 발 생하게 된다. 본 증례에서는 특별히 고안된 전기소작기를 이 용하여 반회후두신경의 갑상연골분지를 수술 시야에서 확인 한 후 선택적으로 빠르게 절제함으로써 주변 정상 조직의 손 상을 최소화하면서 신경재분배의 가능성을 최소화한다. 따라 서 반회후두신경 손상에 의한 성대마비나 과도한 근육 손상 에 의한 수술 후 성대 위축 및 성문폐쇄부전에 의한 흡인 등 호흡 기능 부작용이 발생할 확률이 더 낮을 것으로 예상된다. 본 증례에서도 수술 직후 특별한 합병증이 없었으며 보톡스 주입술을 받은 경우 약 6개월 이후 증상이 재발했으나 수술 후 1 년 추적 관찰 기간 동안 증상의 재발 및 부작용은 보고 되지 않았다. 향후 본 술식에 대한 추가적인 다양한 증례 경 험을 통해 장기적인 치료 효과에 대한 고찰이 필요할 것으로 생각된다.

중심 단어: 연축성발성장애, 갑상피열근, 근절제술, 신경차단.

Acknowledgments

None.

Conflicts of Interest

The authors have no financial conflicts of interest.

Authors' Contribution

Conceptualization: Han Su Kim. Validation: Sung Min Chung, Soo
Yeon Jung. Writing - original draft: So Jeong Lee, Han Su Kim. Approval of final manuscript: all authors.

\section{REFERENCES}

1. Ludlow CL, Adler CH, Berke GS, Bielamowicz SA, Blitzer A, Bressman SB, et al. Research priorities in spasmodic dysphonia. Otolaryngol Head Neck Surg 2008;139(4):495-505.

2. Tsuji DH, Takahashi MT, Imamura R, Hachiya A, Sennes LU. Endoscopic laser thyroarytenoid myoneurectomy in patients with adductor spasmodic dysphonia: a pilot study on long-term outcome on voice quality. J Voice 2012;26(5):666.e7-12.

3. Choi HS. Botox injection for the management of spasmodic dysphonia. J Korean Laryngol Phonia 2012;23(2):99-103.

4. Ludlow CL. Treatment for spasmodic dysphonia: limitation of current approaches. Curr Opin Otolaryngol Head Neck Surg 2009;17(3): 160-5.

5. Dedo HH, Behlau MS. Recurrent laryngeal nerve section for spastic dysphonia: 5- to 14-year preliminary results in the first 300 patients. Ann Otol Rhinol Laryngol 1991;100(4 Pt 1):274-9.

6. Choi HS. Selective thyro-arytenoid (TA) nerve section and ansa cervicalis reinnervation for the treatment of spasmodic dysphonia. J Korean Soc Laryngol Phoniatr Logops 1995;38(2):267-74.

7. Weed DT, Jewett BS, Rainey C, Zealear DL, Stone RE, Ossoff RH, et al. Long-term follow-up of recurrent laryngeal nerve avulsion for the treatment of spastic dysphonia. Ann Otol Rhinol Laryngol 1996;105 (8):592-601.

8. Carpenter RJ III, Snyder GG III, Henley-Cohn JL. Selective section of the recurrent laryngeal nerve for the treatment of spastic dysphonia: an experimental study and preliminary clinical report. Otolaryngol Head Neck Surg 1981;89(6):986-91.

9. Chhetri DK, Mendelsohn AH, Blumin JH, Berke GS. Long-term follow-up results of selective laryngeal adductor denervation-reinnervation surgery for adductor spasmodic dysphonia. Laryngoscope 2006;116(4):635-42.

10. Chan SW, Baxter M, Oates J, Yorston A. Long-term results of type II thyroplasty for adductor spasmodic dysphonia. Laryngoscope 2004; 114(9):1604-8.

11. Kim HS, Choi HS, Lim JY, Choi YL, Lim SE. Radiofrequency thyroarytenoid myothermy for treatment of adductor spasmodic dysphonia: how we do it. Clin Otolaryngol 2008;33(6):621-5.

12. Nakamura K, Muta H, Watanabe Y, Mochizuki R, Yoshida T, Suzuki M. Surgical treatment for adductor spasmodic dysphonia--efficacy of bilateral thyroarytenoid myectomy under microlaryngoscopy. Acta Otolaryngol 2008;128(12):1348-53. 